ARTIGOS

DOI https://doi.org/10.31639/rbpfp.v10i19.185

\title{
NUPEDOC: Formação Humana, Arte, Infância e Pesquisa
}

Luciane Maria Schlindwein (UFSCar) Ilana Laterman (UFSCar) Joselma Salazar de Castro (UFSCar)

RESUMO: O núcleo de pesquisa tem como eixo central dos estudos a formação de professores para a infância e atua na linha de pesquisa Educação e Infância do Programa de Pós-Graduação em Educação da Universidade Federal de Santa Catarina (PPGE/UFSC). Os estudos e pesquisas fundam-se na perspectiva histórico-cultural com foco na escola, na cultura, na arte, na estética e em suas relações com a formação humana e a ação do professor e seus desdobramentos. O Núcleo de Formação de Professores, Escola, Cultura e Arte (NUPEDOC) vem se organizando a partir de quatro eixos: a) formação inicial e continuada de professores para a infância; b) prática de ensino como co-formadora (ênfase na relação escola/universidade); c) desenvolvimento estético de professores e crianças; d) reflexões conceituais e metodológicas pautadas nos pressupostos teóricos e metodológicos de Vigotski e Bakhtin.

PALAVRAS-CHAVE: Formação de professores; infância; psicologia histórico-cultural

\section{NUPEDOC: human training, art, childhood and research}

\begin{abstract}
The main focus of the research group is the formation of teachers for children in the research line Education and Childhood at the Ph.D. Program of the Federal University of Santa Catarina (PPGE / UFSC). The studies and research are based on the historical-cultural perspective. The object the most of research is focused on school, culture, art, aesthetics and its relations with human formation and the action of the teacher and its unfolding. The Núcleo de Formação de Professores, Escola, Cultura e Arte (NUPEDOC) has been organized on four axes: a) initial and continuing teacher training for children; b) teaching practice as a co-teacher (emphasizing the school/university relationship); c) aesthetic development of teachers and children; d) conceptual and methodological reflections based on the theoretical and methodological assumptions of Vigotski and Bakhtin.
\end{abstract}

KEYWORDS: Teacher training; childhood; historical-cultural psychology 


\section{autêntica}

DOI https://doi.org/10.31639/rbpfp.v10i19.185

\section{CONSTITUIÇÃO E HISTÓRIA}

A história de constituição do grupo inicia-se em 1999, com o nome Formação Docente. Na época, estávamos construindo um novo programa de pós-graduação em Educação, em nível de mestrado. O grupo contava com três pesquisadores recém titulados e integrantes do Programa de Mestrado em Educação (PMAE) da Universidade do Vale do Itajaí (UNIVALI). O intuito, na época, era de aglutinar os pesquisadores que estivessem envolvidos nas pesquisas sobre formação de professores, fossem estudos voltados para investigações na formação inicial ou continuada. Tratava-se, portanto, de um grupo pensado e organizado pelo coletivo que compunha aquele programa de pós-graduação. Em 2003, a vinda do professor Angel Pino Sirgado (para compor o quadro de professores permanentes do PMAE) resultou na reorganização do grupo e a alteração do nome para Cultura, Escola e Educação Criadora.

Em dez anos foram orientados 32 trabalhos de conclusão em nível de mestrado. Dentre as dissertações defendidas neste período podemos destacar uma forte implicação e comprometimento com as políticas públicas educacionais (especialmente as locais e ou regionais). Realizamos estudos documentais e bibliográficos, cujo objetivo central foi compreender as bases filosóficas das pesquisas realizadas nos programas de pós-graduação em Educação, no estado de Santa Catarina (HILLESHEIM, 2009). Pesquisas de caráter documental também foram realizados, como no caso da dissertação defendida por Rozilda da Silva Luis (Estado do Conhecimento das Dissertações Defendidas entre os Anos 2002 e 2006), que mapeou todas as dissertações defendidas no PMAE durante os seus primeiros anos de existência (cabe lembrar que o programa teve sua primeira turma matriculada no ano 2000 e as primeiras dissertações foram defendidas no ano de 2002). Este trabalho possibilitou pensar retrospectivamente e perspectivamente a organicidade do PMAE, apresentando indicadores para o planejamento institucional.

Programas oficiais promovidos pelo MEC também foram alvo de pesquisa, como no caso da dissertação defendida por Marcia Regina Cordeiro Bavaresco, em 2004 (As Interfaces de um Programa Oficial de Formação: PROFA - do Escrito à Dinâmica de Formação).

Entre os anos de 2003 e 2006 o grupo recebeu apoio do CNPq (Pró-info) para o projeto: Solftware Educacional para o Ensino Fundamental. Tal pesquisa, apoiou-se em uma metodologia de trabalho multidisciplinar objetivando a construção e avaliação de um software educacional. Tal proposta contou com o apoio da secretaria de educação do município de Blumenau, envolvendo a participação efetiva de dez escolas municipais, pesquisadores e alunos dos cursos de graduação em Ciências da Computação, Design, Letras e Pedagogia da UNIVALI, bem como pesquisadores do PMAE. A construção de um software integrado à proposta curricular de uma secretaria e com a participação efetiva de professores e alunos da rede, foi um diferencial que, resultou na apresentação do SOFTWALI no CRIFPEE, na Universidade de Montreal (Canadá), em 2004. Na época, a utilização de um software educacional no ensino nos anos iniciais do ensino fundamental constituiu-se em ferramenta qualitativa para aprendizagem das crianças em diferentes campos conceituais e possibilitou, ainda, a familiarização de professores e alunos com as novas tecnologias. Assim, para além da metodologia de construção da ferramenta, a pesquisa acompanhou o impacto que o uso do software educacional poderia gerar no Ensino Fundamental. A metodologia de desenvolvimento do software educacional fundamentou-se no "modelo de prototipação", de acordo com o qual, um protótipo é desenvolvido para ajudar no entendimento dos requisitos. O desenvolvimento do protótipo contou com a participação ativa das crianças, professores e gestores em todas as etapas (de projeto, codificação e teste). Outro ponto alto deste estudo foi a base conceitual utilizado no campo da ciência da computação. Os fundamentos da Psicologia Histórico-Cultural constituíram-se no eixo teórico tanto para elaboração pedagógica do software educacional (em consonância 


\section{autêntica}

DOI https://doi.org/10.31639/rbpfp.v10i19.185

com a rede municipal de ensino de Blumenau/SC), quanto das análises que foram empreendidas em relação ao impacto do uso da ferramenta. Cinco trabalhos de iniciação científica, três trabalhos de conclusão de curso e duas dissertações estiveram vinculadas diretamente a esta pesquisa.

Entre os anos de 2002 e 2005 o grupo estruturou-se em torno de uma grande pesquisa interinstitucional, que contou com a participação de professores da UNICAMP (destacadamente o Profo Angel Pino Sirgado), da UFSC, da FURG e da UNIVALI. Partimos de uma pesquisa coletiva e interinstitucional, cujo objeto foi investigar o perfil diagnóstico dos professores dos anos iniciais dos municípios de Itajaí/SC, Florianópolis/SC e Rio Grande/RS. Considerava-se que o contexto social, econômico e cultural no qual o professor se constitui pode ser, efetivamente, indicador de suas escolhas profissionais e, até mesmo, de sua ação pedagógica. Tratava-se, portanto, de buscar indicadores outros, além daqueles apresentados pelo INEP/MEC, que delineiam o perfil acadêmico e profissional do professor. Para os fins deste estudo foi utilizada uma metodologia estatística, a análise multidimensional, apoiada em um software (SPHINKS). Foi construído e aplicado um questionário contendo setenta e oito questões (validado em diferentes pilotos e sob a orientação de técnicos da Fundação Carlos Chagas/SP). Esta pesquisa contou com apoio do edital de apoio à pesquisa da Fundação de Amparo à Pesquisa e Inovação do Estado de Santa Catarina (FAPESC). Desdobraram-se deste estudo as seguintes pesquisas: Perfil dos professores das séries iniciais no município de Balneário Camboriú, (SCHLINDWEIN, 2004) (PIPG/UNIVALI); Perfil Social Econômico e Cultural dos Professores das Séries Iniciais do Município de Itajaí, (SCHLINDWEIN, 2004b) (PIBic/CNPq); Imaginação e Arte na Formação de Professores do Ensino Fundamental (SCHLINDWEIN, 2005) (PIBic/CNPq); Perfil Social, Econômico e Cultural dos Professores do Município de Balneário Camboriú BIGATON, 2005 (dissertação de mestrado); Professora: sujeito em formação, MACHADO, 2005 (dissertação de mestrado, CNPq); Olhares, Significações e Silêncios: a Produção de Conhecimentos na Prática de Ensino, (PETRI, 2006) (dissertação de mestrado, CNPq); (NADALETO, 2007); A Formação Estética do Professor do Ensino Básico: o papel da música (SCHLINDWEIN, 2006-2008) (FAPESC); Educação Estética - Investigando Possibilidades a Partir de um Grupo de Professoras, (SOARES, 2008) (dissertação de mestrado, CNPq).

Tais pesquisas já indicavam, na época, a abertura do grupo de pesquisa para a utilização de metodologias que atendessem as necessidades das próprias investigações, de modo que teoria e método pudessem constituir uma organicidade metodológica nas investigações realizadas. Nesta perspectiva, compreendemos que o materialismo histórico e dialético, que se constitui em matriz de referência da perspectiva histórico-cultural delineada por Vigotski (1896-1934) vem norteando nossas pesquisas no grupo. A história dos fenômenos investigados (ou seja, o processo que gera a sua existência como fenômeno e não apenas o fenômeno em si mesmo) e o caráter dialético desses processos são elementos constitutivos das próprias pesquisas.

No capítulo 2 do tomo II das Obras Escogidas (1995/1931), Vigotski destaca que um dos princípios metodológicos fundamentais na pesquisa é a existência de uma íntima relação entre teoria e método. Se, por um lado, a teoria permite ao pesquisador modos diferenciados de "olhar" o objeto de investigação, o método possibilita à teoria provar-se nos resultados deste objeto ou encontrar elementos para a sua reelaboração. Poder-se-ia afirmar que o "modo de olhar" o objeto determina o método mais adequado para chegar aos objetivos que aponta esse mesmo "modo de olhar", mas que a natureza do objeto determina, por sua vez, a maneira de ser olhado.

Faz-se necessário, capturar a história, com o objetivo de compreender o sentido que esta tem para Vigotski: Estudar algo historicamente significa estudá-lo em movimento. Esta é a exigência fundamental do método dialético. Quando, em uma investigação, se pretende compreender o processo de desenvolvimento de algum 


\section{autêntica}

DOI https://doi.org/10.31639/rbpfp.v10i19.185

fenômeno em todas as suas facetas e transformações, desde seu início até o final. Isso implica colocar em questão sua natureza, conhecer sua essência, uma vez que, somente em movimento expressará o todo. Assim pois, a investigação histórica do comportamento não é algo que complementa ou auxilia a teoria, mas se constitui em seu fundamento. (Vigotski, 1995, p. 67-68)

É preciso compreender que a história é sempre capturada em seus fragmentos, por mais que se busque a totalidade. Neste sentido, buscamos apreender os traços, pistas e marcas enquanto elementos que possam compor a tessitura de uma história a ser interpretada. De acordo com Ginzburg, "pistas talvez infinitesimais permitem captar uma realidade mais profunda, de outra forma inatingível" (1989, p. 34).

Entre os anos de 2004 e 2006 investimos nossos esforços, no grupo, em uma pesquisa longitudinal, com o intuito de compreendermos os processos de aprendizagem de professores para o ensino fundamental. Em uma parceria com a universidade, especialmente com o curso Pedagogia, investimos em uma formação diferenciada, aliando teoria e prática, arte e cultura. A vivência e a tomada de consciência, dois conceitos-chave na abordagem histórico-cultural, passam a ser balizadores de nossa investigação.

Constituímos um grupo com 12 alunas, no início do ano de 2004. Todas as alunas estavam regularmente matriculadas no curso de Pedagogia e as atividades de vivências estéticas foram realizadas no âmbito da disciplina de Prática de Ensino. Participaram deste primeiro momento de formação as duas professoras regentes, dois pesquisadores do grupo de pesquisa e três artistas plásticas. O foco das atividades desenvolvidas, neste primeiro semestre letivo, foi a vivência nas artes visuais. A história da arte, a mulher na história da arte, a leitura e releitura da obra de arte e o fazer artístico foram as principais temáticas abordadas nas vivências. No segundo semestre, atividades de sensibilização musical foram incluídas, uma vez que passamos a contar com uma musicista no grupo de pesquisa. Em 2005, o conteúdo das vivências foi ampliado, incluindo teatro, cinema e literatura. A partir de 2006, contamos, também, com a colaboração ativa de uma professora/pesquisadora da área da literatura. Desta forma, o grupo passou a contar com a participação de artistas plásticos, musicistas, literatos e uma dramaturga. As atividades de vivência propiciaram o envolvimento das alunas com as diferentes possibilidades de manifestações artísticas. Os encontros foram registrados em videocassete e memoriais escritos pelas alunas/professoras 1 envolvidas. Cabe lembrar que no início da pesquisa, em março de 2004 as envolvidas na pesquisa eram todas alunas do curso Pedagogia, matriculadas regularmente no sexto período do curso. Com a conclusão do curso, em julho de 2005, foram convidadas a continuar participando da pesquisa. A participação nos semestres seguintes (2005/2, 2006/1 e 2006/2) aconteceu na modalidade de formação continuada, com direito a certificado de 80 horas/aula por semestre.

Percebemos que as análises dos memoriais e das transcrições das gravações em vídeo, de cinco semestres de investimento em outras leituras de mundo (transpassadas pelo viés artístico), pareciam não indicar grandes transformações nas posturas das professoras. E, percebemos, ainda, uma grande necessidade das professoras em replicarem o que era vivenciado nos ateliês, em suas salas de aula (o que nem sempre resultava em frutos profícuos). Estas duas questões nos mobilizaram a fazer uma avaliação dos ateliês de estética e de seu impacto nas envolvidas. Resolvemos que no segundo semestre de 2006 investiríamos em uma formação para o desenvolvimento estético da pessoa (do professor). Cabe ressaltar que, do ponto de vista das professoras envolvidas, elas estavam realizando uma formação continuada, o que acabou gerando uma expectativa em torno de soluções para as problemáticas evidenciadas em seus cotidianos pedagógicos. A

\footnotetext{
1 Nos três primeiros semestres as 12 participantes eram alunas do curso Pedagogia. Nos três semestres seguintes, estas passaram a ser professoras no ensino fundamental e na educação infantil. 


\section{autêntica}

DOI https://doi.org/10.31639/rbpfp.v10i19.185

partir de uma discussão coletiva (e avaliativa), envolvendo os pesquisadores e as professoras, definimos que nossa intencionalidade (enquanto pesquisa) estaria focada na formação da pessoa (e não, necessariamente, do professor). Ou seja, nosso objetivo declarado, junto a nossos sujeitos de pesquisa, passou a ser o de promover vivências estéticas para que elas pudessem fruir descompromissadamente, pelo simples deleite de vivenciar contatos com as diferentes manifestações artísticas (especialmente a música e a literatura). Consideramos que, como não se pode descolar o professor da pessoa do professor, os reflexos de uma formação pessoal seriam sentidos na trajetória educacional das envolvidas.

Realizamos, ao longo do segundo semestre de 2006, cerca de 80 horas de formação estética, privilegiando a música e a literatura de forma quase intensiva. Encerramos nossos trabalhos com este grupo de professoras com um sarau literário e musical. As professoras envolvidas puderam expressar suas construções artísticas e vivenciar experiências estéticas de criação e apreciação. Neste mesmo encontro, as professoras registraram, por escrito, suas percepções estéticas em um plano de elaboração conceitual, imaginário e afetivo.

Apoiados na perspectiva histórico-cultural, especialmente nos estudos desenvolvidos por Vigotski (1999), compreendemos que o ser humano se constitui em contextos culturais e históricos definidos. Para o autor, o sentido estético é construído na interface entre o objeto estético, a realidade e a possibilidade do homem de atribuir significação. Nesta perspectiva, é possível considerar a hipótese de diferentes entendimentos para o belo, para o bonito, para o estético. A significação é compreendida como um fenômeno cultural de agrupamentos humanos inseridos em espaços e tempos definidos. E, como atividade coletiva, implica, necessariamente, em acordos. O sentido estético ocupa, portanto, um lugar social estabelecido em um espaço simbólico, significado culturalmente. As concepções e os valores subjacentes a estas concepções (BAKHTIN, 2003) são construídos em contextos de significação ao longo das histórias de vida. Ou seja, as interferências de ordem cultural podem desencadear novas formas de significações. De acordo com Pino:

Um componente da tese de Vigotski do "desenvolvimento cultural" (do homem) é a sua capacidade de simbolizar, ou seja, de criar símbolos e significar as coisas. [...] No campo da sensorialidade e da sensibilidade isso se traduz na capacidade de atribuir um sentido - o que equivale a dar significações sociais atribuídas às coisas - às produções do imaginário, às imagens formadas como resultado da sensorialidade e ao conjunto das produções imaginárias resultantes do remanejamento dessas imagens e da criação de outras novas sem vínculo direto com a percepção sensorial (PINO, 2006, p. 67-68).

O fazer artístico propicia à pessoa um trabalho completo, envolvendo o intelecto, os sentidos, a emoção e os conhecimentos adquiridos - mesmo que já construídos, passíveis de mudanças. Uma educação pautada nas artes propicia o desenvolvimento do pensamento artístico e da percepção estética, que caracterizam um modo próprio de ordenar e dar sentido à experiência humana. A pessoa desenvolve sensibilidade, percepção e imaginação, na medida em que aprende a apreciar diferentes manifestações artísticas, atribuindo-lhes significados diversos e podendo, inclusive, transformá-las (SCHLINDWEIN, 2006).

Nesta pesquisa longitudinal, as vivências/experiências estéticas foram registradas em videocassete; contamos, também, com um diário de campo e com material gráfico e técnico produzidos pelas professoras. Destacamos o registro das percepções das envolvidas, no que denominamos memoriais. Os memoriais são registros escritos pelas próprias professoras, ao final de cada encontro, nos quais são anotados sentimentos, percepções, críticas e sugestões das atividades desenvolvidas (SCHLINDWEIN \& NADALETO, 2007). O que ocorre é que, com o uso sistemático dos memoriais, as professoras passaram a avaliar suas trajetórias, revendo-se e se reinventando. 


\section{autêntica}

DOI https://doi.org/10.31639/rbpfp.v10i19.185

Foram organizadas vivências estéticas e momentos de reflexão sobre diferentes manifestações artísticas. Tínhamos o duplo objetivo de proporcionar uma ampliação de repertório conceitual e cultural das professoras envolvidas e, ainda, pela via da reflexão e autorreflexão (instrumentalizada especialmente pelos memoriais), criar possibilidades de lhes mobilizar a percepção e a imaginação.

\section{FORMAÇÃO DE PROFESSORES PARA A INFÂNCIA}

Em 2009, com a saída da coordenadora do grupo para a Universidade Federal de Santa Catarina (UFSC), novos desafios se apresentam. Considerando a importância de continuidade nos estudos realizados durante dez anos de pesquisa, o Grupo de Pesquisa Cultura, Escola e Educação Criadora foi delegado para uma das pesquisadoras que permaneceu na UNIVALI.

Na UFSC, contando com a participação de pesquisadores de outras instituições, tais como Universidade da Região de Blumenau (FURB), Universidade da Região de Joinville (UNIVILLE) e da Universidade Católica do Paraná (PUC/PR) constitui-se o Núcleo de Pesquisa Formação de Professores, Escola, Cultura e Arte (NUPEDOC).

O nome núcleo e não grupo se efetiva, justamente, porque a proposta pensada com as pesquisadoras envolvia uma perspectiva de realização de pesquisas interinstitucionais sobre a formação de docente. Tal proposta tomou um rumo bastante profícuo, constituindo-se, hoje na Rede Interinstitucional de Pesquisadores sobre Formação e Práticas Docentes (RIPEFOR).

A Rede Interinstitucional de Pesquisas de Formação e Práticas Docentes - RIPEFOR tem por objetivo aproximar grupos de pesquisa que pesquisam formação de professores, na Região Sul do Brasil. A rede é constituída por pesquisadores das seguintes universidades: Universidade da região de Joinville - UNIVILLE, Universidade Federal de Santa Catarina - UFSC, Universidade Estadual de Ponta Grossa - UEPG, Universidade Tecnológica Federal do Paraná - UTFPR, Instituto Federal Sul-Rio-Grandense IFSUL, Universidade Federal de Pelotas UFPEL, Universidade Regional de Blumenau - FURB, Pontifícia Universidade Católica do Paraná - PUCPR, Centro Universitário Internacional - UNINTER. O termo de cooperação entre os grupos constituintes da rede foi assinado no ano de 2016, firmando oficialmente o convênio. Celebram o convênio, os seguintes grupos e núcleos de pesquisa: Núcleo de Formação de Professores, Escola, Cultura e Arte - NUPEDOC/UFSC, Grupo de Estudos e Pesquisas sobre o Trabalho e a Formação Docente - GETRAFOR/UNIVILLE, Grupo de Estudos e Pesquisa sobre o Trabalho Docente - GEPTRADO PPGE/UEPG, Grupo de Pesquisa sobre o Desenvolvimento Profissional Docente - TRANSMUTARE/UTFPR, Grupo de Estudos Narrativos em Educação - GENE/IFSU. A professora Ruth Mercado Maldonado, do Departamento de Investigações Educativas do CINVESTAV/México tem sido uma parceira nas reuniões da rede. A rede tem promovido duas reuniões anuais de caráter itinerante, consolidando-se como espaço de produção de conhecimento no campo da formação de professores.

O NUPEDOC (http://nupedoc.ufsc.br/) constitui-se em núcleo de pesquisa vinculado ao Programa de Pósgraduação em Educação da Universidade Federal de Santa Catarina (PPGE/UFSC). Conta com a participação efetiva de oito pesquisadores, dos quais três são professores vinculados ao Departamento de Metodologia de Ensino do Centro de Educação da UFSC (MEN/CED) e ao PPGE; três são egressas do PPGE (duas com vínculo na rede pública municipal de Florianópolis e uma na rede estadual de SC) e, uma pesquisadora da Universidade de Girona (UGD), Catalunha, Espanha. Tem como eixo central dos estudos a formação de professores para a infância e atua na linha de pesquisa Educação e Infância do Programa de Pós-Graduação da Universidade Federal de Santa Catarina (PPGE/UFSC). 


\section{autêntica}

DOI https://doi.org/10.31639/rbpfp.v10i19.185

O núcleo desenvolve estudos na perspectiva histórico-cultural com foco na escola, na cultura, nas artes, na estética e em suas relações e implicações com a formação e a ação do professor e seus desdobramentos na constituição do ser humano. O NUPEDOC se organiza a partir de quatro eixos: a) formação inicial e continuada de professores para a infância; b) prática de ensino como co-formadora (ênfase na relação escola/ universidade); c) desenvolvimento estético de professores e crianças; d) reflexões conceituais pautadas nos pressupostos teóricos e metodológicos de Vigotski e Bakhtin.

Na perspectiva histórico-cultural desenvolvida por Vigotski, quanto mais as pessoas ampliam e diversificam suas experiências, maiores as possibilidades de desenvolverem um pensamento mais imaginativo. Para Vigotski: "a imaginação está muito arraigada ao conteúdo de nossa memória" (VIGOTSKI, 1982, p. 426). Experiência e memória garantem o conteúdo para o pensamento imaginativo. E a imaginação está no cerne da criação humana. Nesta linha de pensamento, consideramos interessante investirmos em pesquisas que investiguem os processos constitutivos do professor a partir de um viés artístico (especialmente as artes visuais, música e literatura).

Consideramos que uma série de fatores vem contribuindo para a fragmentação dos conteúdos que subsidiam o ensino, especialmente nos anos iniciais do ensino fundamental. Vimos acompanhando, a cada nova geração, uma espécie de empobrecimento de referências culturais e de contextualização dos conteúdos mais básicos. Tais fatores se refletem na aquisição e no uso da linguagem escrita, de uma forma crucial. As professoras (muitas vezes porque elas próprias não foram apresentadas à leitura como prazer) acabam desenvolvendo, por exemplo, uma prática pedagógica na qual a literatura se restringe àquela apresentada nos livros didáticos, sem ter acesso ao contexto mais amplo no qual esta obra está inserida. Ou seja, o texto fragmentado é o único acesso à literatura ao qual professores - e alunos, em decorrência - têm acesso. Consequentemente, as inferências e relações entre o conteúdo e a vida da criança são nulas ou precárias, resultando em um conteúdo estéril e que pouco tem a ver com o interesse das crianças, muitas vezes, inclusive, afastando-as dos livros e da linguagem escrita em geral, de maneira irremediável.

Em sua estrutura formal e tal como está credenciado na plataforma de grupos do sistema lattes, o NUPEDOC possui três linhas de pesquisa, a saber: a) Desenvolvimento estético de professores e alunos, b) Educação e Infância e c) Formação inicial e continuada de professores para a infância. A linha desenvolvimento estético de professores e alunos tem por objetivo investigar a constituição da subjetividade humana em uma perspectiva histórico-cultural, apoiados, especialmente, nos pressupostos teóricos e metodológicos de Bakhtin e Vigotski. A linha educação e infância tem por objetivo realizar estudos e pesquisas sobre a educação da infância e o processo de produção de conhecimento nesta área, suas especificidades no campo educacional relacionadas às práticas pedagógicas, à formação docente e às políticas educacionais. A linha de pesquisa formação inicial e continuada para a infância tem por objetivo compreender as diferentes dinâmicas dos processos de ensino e aprendizagem dos professores para a educação básica.

Neste período de quase dez anos (2009-2018), foram concluídas três pesquisas de doutorado, das quais destacamos a tese "A Docência na Educação Infantil como Ato Pedagógico", defendida por Joselma Salazar de Castro (2016) que contou com bolsa PDSE/CAPES. Tal mobilidade acadêmica permitiu a efetivação de intercâmbio entre o NUPEDOC e as professoras Dr ${ }^{a}$ Anna Maria Bondioli e Dra . Donatella Savio, ambas da Università degli Studi di Pavia, na Itália. Outro destaque refere-se à teses defendida por Claudete Bonfanti (2017): “O estágio na formação de professoras para a Educação Infantil: as significações das estagiárias de um curso de Pedagogia". A pesquisa também contou com bolsa PDSE/CAPES. Foi realizada na Universidade de Florença (Università degli Studi di Firenze - Unifi), com a supervisão da professora Dra Clara Silva. Tais 


\section{autêntica}

DOI https://doi.org/10.31639/rbpfp.v10i19.185

atividades acadêmicas resultaram em convênios e produções colaborativas entre o NUPEDOC e os grupos de pesquisa das professoras italianas.

As produções acadêmicas realizadas no período refletem o nosso compromisso com a formação humana e do pesquisador. Foram concluídas, também, oito dissertações de mestrado, trabalhos de conclusão de curso e pesquisas de iniciação científica.

\section{TEORIA E MÉTODO}

A formação de professores vem sendo investigada, no âmbito do NUPEDOC, a partir de uma perspectiva dialética, na qual busca-se compreender processos. Destacamos os processos de aprendizagem do professor, seja em termos conceituais, durante sua formação inicial ou continuada; processos de constituição da profissionalidade docente; processos de ensino e prática pedagógica docente; desdobramentos das políticas locais, regionais e nacionais de educação, entre outros. Neste sentido, os estudos vem se apoiando, principalmente em autores tais como Vigotski, Bakhtin, Freinet e seus interlocutores contemporâneos. Estudos sobre a aprendizagem e desenvolvimento balizam grande parte das pesquisas realizadas no núcleo.

Vigotski atribui grande ênfase ao papel da linguagem na mobilização da aprendizagem e do desenvolvimento. A relação que se estabelece entre os processos de linguagem e pensamento implica em diferentes transformações em ambos. A estrutura da linguagem não se restringe a um simples reflexo da estrutura do pensamento. Para o autor, "o pensamento não se expressa, mas se realiza na linguagem" (VIGOTSKI, 2001, p. 412). O autor faz uma distinção entre duas instâncias da palavra: seu significado e seu sentido. Para o autor, o significado das palavras constitui uma zona de estabilidade - que podemos definir como zona dicionarizada, delimitada em sua conotação de significado -, que garante a comunicação entre as pessoas. Já o sentido é uma produção dotada de mobilidade dinâmica no discurso, constituída por diferentes zonas parciais de estabilidade, uma das quais - a mais estável - constitui o significado.

O sentido é sempre uma formação dinâmica, fluida, complexa, que tem várias zonas de estabilidade variada. O significado é apenas uma dessas zonas do sentido que a palavra adquire no contexto de algum discurso e, ademais, uma zona mais estável, uniforme e exata. [...] O sentido real de uma palavra é inconstante (VIGOTSKI, 2001, p. 412).

A partir desta concepção, entendemos que a aprendizagem escolar deve transcender a apreensão da zona mais estável do significado, a aquisição dos conhecimentos científicos culturalmente estabelecidos; da mesma forma que a sensibilidade dos professores deve transcender o significado pré-conceituado, a respeito das manifestações de seus alunos, em direção à fluidez do significado. A atividade escolar deve, além disso, promover aquelas situações vivenciais de estranhamento que mergulhem na formação fluida do sentido, nas zonas mais instáveis em que têm vez os campos da criatividade e da imaginação. A contradição entre a fluidez criativa do sentido e a norma, a nosso ver, não é algo a ser evitado, mas parte do processo dinâmico na história do humano. Como parte deste processo, consideramos que nossas intervenções e pesquisas possam transformar o sentido que os professores - e, por extensão, as crianças - atribuem ao conhecimento.

Consideramos que a tomada de consciência tem a ver, necessariamente, com os sentidos e os valores atribuídos pela criança (bem como pelos adultos) aos novos conteúdos. A auto percepção dos sentimentos despertados pela vivência são essenciais para o processo de tomada de consciência. De acordo com Damásio, quando os sentimentos se tornam conhecidos para a pessoa há uma tendência ampla de melhorar e amplificar 


\section{autêntica}

DOI https://doi.org/10.31639/rbpfp.v10i19.185

o processo pessoal de autogoverno. Para o autor, "a aprendizagem e a recordação dos objetos e situações emocionalmente competentes são também apoiadas pela presença dos sentimentos" (DAMÁSIO, 2004, p. 191). Os estudos realizados pelo autor consideram que a memória de situações vivenciadas, sentidas, tende a promover situações que causam sentimentos positivos.

A tomada de consciência dos próprios sentimentos e vivências é particular a cada ser humano. Trata-se de algo constituído nas trocas sociais, e pelas trocas sociais, que será convertido em próprio, em específico de cada pessoa. A tomada de consciência é particular a cada um em sua relação com a experiência estética. Mas, mais do que isto, a tomada de consciência pela via da sensibilidade estética também se trata de uma experiência particular para cada professor em sua formação. E consideramos que esta vivência particular the permitirá ampliar a sua atitude crítica em relação aos valores subjacentes à cultura da qual faz parte, que lhe servem como referência - constituindo sua ética - muitas vezes de forma implícita e menos consciente. É assim que compreendemos a potencialidade criadora possibilitada pela Estética na formação ética dos professores.

Consideramos que cada ação do homem constitui-se em uma experiência única, que reflete suas percepções mais idiossincráticas, estas constituídas ao longo de sua trajetória de vida. Da mesma forma, o professor, ao assumir o seu papel de mestre, de mediador, de orientador, ao mesmo tempo em que experiencia algo novo a cada atividade docente, traz consigo as marcas que o formaram e que estão arraigadas ao seu modo de ser e de fazer. Entretanto, por mais que sejam particulares e pessoais, as experiências se efetivam em espaços coletivos, repletos de valores que superam os limites do individual. Consideramos que estes valores constituem-se coletivamente, a partir das relações que vão sendo articuladas, em espaços e tempos determinados. De acordo com Ostrower (2007), os aspectos valorativos são essencialmente coletivos, originados em contextos históricos determinados, formam a base das instituições e das normas, constituindo o corpo de ideias de uma dada cultura. Para a autora: "São as valorações da cultura em que vive o indivíduo, os chamados valores de uma época. Representam o padrão referencial básico para o indivíduo, que qualifica a própria experiência pessoal e tudo a que o indivíduo aspire ou o que faça, quer tenha ele consciência ou não" (OSTROWER, 2007, p. 52).

Este padrão referencial subjaz à forma como a realidade é esteticamente percebida e estruturada pelo professor, de maneira que sua flexibilização permitirá uma atitude crítica em relação à própria realidade. A atenção, portanto, às questões estéticas torna-se essencial quando tratamos de formação de professores. É neste contexto que propomos a pertinência do estudo da estética na formação de professores e que nos propomos a discutir a articulação entre uma concepção dialética da estética e a formação de professores.

Para Vigotski (1999), a percepção estética supõe um movimento que envolve contradição, transformação e que se assemelha, portanto, ao movimento de catarse, no qual acontece uma espécie de conversão de sentimentos. De acordo com Kozulin (1994), Vigotski apoiou-se na obra de Aristóteles (Poética) para definir catarse: uma espécie de descarga de emoções que um espectador acumula ao defrontar-se com uma obra de arte. Para Vigotski a catarse permite não somente a descarga de tensões, mas considera que, ao promover uma descarga afetiva, o homem transforma os seus próprios sentimentos. Assim, a catarse possui uma dupla função, a "reação estética supõe uma complexa transformação dos sentimentos" (VIGOTSKI, 1999, p. 270). Continua o autor:

Podemos levantar a questão de modo bem mais amplo e falar não só da emoção lírica, mas distinguir, em qualquer obra de arte, as emoções suscitadas pelo material e as emoções suscitadas pela forma (...) essas duas séries de emoções estão em permanente antagonismo, estão direcionadas 


\section{autêntica}

DOI https://doi.org/10.31639/rbpfp.v10i19.185

em sentidos opostos e, da fábula à tragédia a lei da reação estética é uma só: encerra em si a emoção que se desenvolve em dois sentidos opostos e encontra sua destruição no ponto culminante, como uma espécie de curto-circuito (VIGOTSKI, 1999, p. 270).

Nesta perspectiva, a reação catártica à forma e ao conteúdo do material estético constitui-se em uma espécie de ferramenta psicológica, sendo constitutiva da própria subjetividade do homem. "Estas transformações afetivas não ocorrem de modo espontâneo, mas exclusivamente sob a influência de mecanismos semióticos específicos que distinguem um gênero artístico determinado e lhe conferem seu valor estético" (KOZULIN, 1994, p. 57). A reação estética significa a possibilidade emocional de uma pessoa frente a alguma coisa que a provoque (como, por exemplo, uma obra de arte, uma música ou um texto literário), ou seja, a capacidade de perceber e se emocionar com tal percepção. Para Vigotski, "a natureza da arte sempre implica algo que transforma, que supera o sentimento comum, e aquele mesmo medo, aquela mesma dor, aquela mesma inquietação, quando suscitadas pela arte, implicam o algo a mais acima daquilo que nelas está contido" (VIGOSTKI, 1999, P. 307). Trata-se, aqui, portanto, de uma concepção dialética e transformadora da estética.

Esta concepção dialética de estética engloba, ao mesmo tempo, a imaginação e o ato criador, ampliando a ideia de uma estética que apenas instrumentalize o homem para perceber o belo ou a arte. Para o Vigotski, a estética origina-se da imaginação, permitindo ao homem organizar o meio no qual está inserido. Configurase um circuito a partir de uma operação dual na qual, ao mesmo tempo em que a pessoa forja o conteúdo dado, seus sentidos são desafiados.

Ao se defrontar e se implicar com um novo conteúdo, o homem transforma-se, modificando não só suas considerações sobre o novo, mas suas próprias percepções. De tal forma que, nesta compreensão, a estética não é um campo restrito à arte, mas abrange múltiplas situações do cotidiano. "A vivacidade esteticamente gerenciada é o resultado do cultivo e do refinamento da percepção. Não é uma questão de arte ou vida. A vida pode oferecer situações mais interessantes em seus envolvimentos imaginários do que qualquer romance" (PFEIFFER, 2001, p. 90).

Somente um modo de pensar dialético parece ser capaz de delimitar o caráter contraditório e paradoxal do significado atribuído à estética, articulando a natureza e a cultura, o material e o simbólico. É sob esta óptica que a estética, incluída na formação dos professores, pode ser considerada como conteúdo fundamental para o desenvolvimento da percepção, da atitude crítica e da atividade imaginária e criativa, elementos que consideramos primordiais ao professor, uma vez que ampliam sobremaneira sua margem de ação formativa diante da aprendizagem e desenvolvimento de seus alunos.

Um trabalho formativo no campo da educação estética pode, assim, desenvolver nos professores o estranhamento, a perplexidade. Não só a contemplação da obra de arte, mas, principalmente, a construção de algo novo diante realidade, pela mobilização da atividade imaginativa.

Outra base conceitual que orienta as pesquisas no Núcleo pauta-se nos autores Pichòn-Rivière; Jorge Visca; Agnes Heller; Hannah Arendt, Celestin Freinet. São pesquisas que buscam coerência entre as atividades de ensino e extensão. Este conjunto de autores da filosofia, psicologia social, pedagogia e teoria histórico-cultural articulam-se em pesquisas, no sentido de buscar compreender processos de aprendizagem de crianças, professores, professores em formação inicial e de escolas, que como organizações complexas, transformam-se na medida da intenção e da aprendizagem das pessoas que a constituem. 


\section{autêntica}

DOI https://doi.org/10.31639/rbpfp.v10i19.185

A pesquisa guarda-chuva que abriga e articula interesses aparentemente diversos no campo da formação de professores e da prática pedagógica intitula-se: Campo de possibilidades da prática pedagógica (LATERMAN, 2005). A ideia de campo resultou de pesquisas sobre o cotidiano escolar e no conceito de cotidiano e da ação humana no cotidiano de Agnes Heller (1992), e tem sustentado investigações que buscam apontar possibilidades de mudanças em contextos específicos. Por exemplo, escolas públicas que já realizam trabalhos bem sucedidos na perspectiva do ensino, da formação e da sociabilidade (das crianças e também dos adultos das escolas); e também contextos onde realizam-se mudanças significativas nos processos a partir de intervenções possíveis com ajuda de assessoria externa à escola. Estas intervenções possíveis são identificadas em processos de assessoria do tipo formação continuada, discussão de cotidiano, inserção no campo por meio da prática de ensino com graduandos da Pedagogia. De tal modo que a pesquisa guarda-chuva está intimamente entrelaçada com ensino e extensão.

A proposta de compreender a ação pedagógica na escola como um campo de possibilidades decorre do fato de a ação docente ocorrer no contexto de uma realidade circunscrita por elementos de políticas públicas, orientações oficiais e condições institucionais. A pesquisa diferencia "o que é possível" e "o que é provável" na prática pedagógica nas escolas. Se por um lado já foi exaustivamente criticado o ensino que reproduz a si mesmo, aqui a ideia é mostrar e contribuir para aquilo que amplia o que se pode realizar no cotidiano.

Entendo a ideia de campo de possibilidades como um conjunto de elementos que compõem o repertório das alternativas possíveis para a ação. Elementos que, ao serem combinados, desestruturados, reestruturados, relacionados de diferentes formas, indicam as ações possíveis na realidade. Tais elementos são sempre combinados entre as dimensões da subjetividade e do meio (político, social, cultural), neste trabalho, da compreensão e intenção individual e das orientações públicas institucionalizadas.

(...)

Portanto, o campo de possibilidades propõe que a ação, mesmo que inovadora, terá como fundamento elementos já postos na realidade, como condição para sua existência concreta. (LATERMAN, 2005.p.2-3)

Mas como fugir ao determinismo e de fato propor possibilidades na ação em escolas concretas, para de fato propor elementos novos que possíveis de serem incorporados a uma prática impliquem em mudanças organizativas do trabalho pedagógico?

Ao agir, o professor elege uma entre tantas possibilidades; sua percepção limita e delimita o campo de possibilidades, pois não há sujeito capaz de perceber todas as alternativas de ação. As alternativas que estão fora de seu alcance perceptivo não são, verdadeiramente, possibilidades de ação. Por esta razão, o campo de possibilidades é efetivamente delimitado por sua percepção e pela compreensão que tem das circunstâncias da realidade. As circunstâncias, ao mesmo tempo em que limitam o rol de ações, delimitam e configuram um princípio de ação. (LATERMAN, 2010. p. 4)

Nesta perspectiva, a discussão de cotidiano em escola pública e junto com as professoras observamos juntas as crianças na brinquedoteca e, por exemplo, compreendemos melhor sobre como aquele grupo específico organizava sua atenção ao brincar e interagir. Com isso, em nossos debates e estudos, foi possível modificar mediações em sala de aula, eliminando hábitos de controle forçadamente excessivo da atenção, para um novo entendimento sobre aquelas crianças (LATERMAN, 2009). 


\section{autêntica}

DOI https://doi.org/10.31639/rbpfp.v10i19.185

Ainda na perspectiva do campo de possibilidades da prática pedagógica e da integração entre pesquisa, ensino e extensão, realizamos na Prática de Ensino, que em nosso currículo tem por disciplina o Estágio Supervisionado em anos iniciais do ensino fundamental, junto com as estudantes estagiárias, atividade do tipo aprendizagem baseada em resolução de problemas. A supervisora da escola nos informou sobre dificuldades relacionadas a agressividade das crianças no recreio. As crianças já estavam sem direito ao parquinho, à bola, situação piorando. Observamos, analisamos, propusemos soluções e modificamos não apenas durante a nossa presença, mas também com novas formas de fazer depois do final de nosso tempo na escola (LATERMAN, 2017).

Mais recentemente os estudos sobre a brinquedoteca escolar têm se configurado como um fator de influência no ensino e no cotidiano.

Considerando que as políticas e as condições macrossociais determinam de modo relevante as possibilidades do cotidiano escolar, em meio às contradições das próprias condições e da ação humana, as pesquisas despretensiosamente buscam valorizar o microssistema, as vidas cotidianas e o bem-estar das pessoas daquele contexto específico.

\section{PESQUISAS REALIZADAS E EM ANDAMENTO}

Ao longo destes quase vinte anos de existência, o NUPEDOC realizou pesquisas apoiadas financeiramente pelo CNPq, CAPES, FAPESC, PIBIc, PDSE, PVE/CAPES. Considera-se que o investimento em educação, cada vez mais restrito, vem se constituindo em limitações reais ao desenvolvimento da pesquisa. Apresentamos, a seguir, as pesquisas em andamento, vinculadas ao PPGE/UFSC:

Dissertações de Mestrado em andamento:

ERICA RODRIGUES VIEIRA. A Arte como Experiência Estética na Prática Pedagógica: um estudo teórico sobre o que pensam e o que fazem os professores da infância. Início: 2016. Bolsa CNPq.

DANIELA GONÇALVES. Alfabetização e Estética. Início: 2017.

Teses em andamento:

Deborah Esther Grajzer. Crianças refugiadas: um olhar para infância e o direito à educação. Início: 2018. Bolsa CAPES.

Gyane Karol Santana Leal. Infância no contexto amazônico: produção cultural das crianças pequenas nas escolas ribeirinhas do município de Parintins-AM. Início: 2018.

Aline Santana Martins. Infância e Teatro nos Anos Iniciais do Ensino Fundamental. Início: 2016. Bolsa CAPES

Matheus Vinicius Fernandes. Atividades de criação em teatro na escola: perspectivas vigotskianas para pensar o jogo e o Drama. Início: 2016.

Caroline Guião Coelho Neubert. Registrar, Investigar e compartilhar: a pesquisa como eixos de produção do conhecimento na educação básica. Início: 2015. Bolsa CNPq

Patrícia Peruzzo. O significado das mídias audiovisuais no processo contemporâneo de construção do conhecimento. Início: 2015.

Mariana Datria Schulze. Trabalho e Formação Docente. Início: 2014. 


\section{autêntica}

DOI https://doi.org/10.31639/rbpfp.v10i19.185

\section{DISSERTAÇÕES CONCLUÍDAS:}

Jussara Bezerra de Souza. O BRINCAR NA INFÂNCIA: o que dizem os documentos escolares de CRUZEIRO DO SUL, no ACRE. 2018.

DEBORAH ESTHER GRAJZER. CRIANÇAS REFUGIADAS: UM OLHAR PARA INFÂNCIA E SEUS DIREITOS. 2018. Bolsa CNPq

Maria Luiza de Souza e Souza. Aprendizagem e infância: um estudo das políticas públicas no município de Florianópolis/SC. 2017. Bolsa CNPq

Roseli Correia de Barros Casagrande. Ensino de Nove Anos e a Formação de Professores. 2015.

Wanessa Bruna Santos Brito. A aprendizagem do alemão como segunda língua nos anos iniciais: uma experiência cultural. 2014. Bolsa CAPES

Ricardo Casarini. O uso da fotografia como elemento de construção dos sujeitos e possível instrumento educativo. 2012. Bolsa CAPES

Caroline Guiao Coelho Neubert. Os sentidos atribuídos pelas crianças aos seus cadernos escolares. 2011. Bolsa CAPES

Silviane Irulegui Bueno. Os deveres escolares para que, para quem?. 2011.

Rozilda da Silva Luis. Estado do conhecimento das dissertações defendidas entre os anos 2002 e 2006 no programa de mestrado em educação da UNIVALI. 2009.

Nelson José Hillesheim. Vertentes filosóficas e os estudos sobre formação de professores na pós-graduação em educação no estado de Santa Catarina. 2009.

Silvana Maria da Rocha. Experiência Estética em Sala de Aula: um estudo a partir de metodologias de museus no ensino da arte. 2009.

Rodrigo Marcelo Wzorek. Motivos e Razões dos Professores das Disciplinas Específicas frente a Carreira Docente. 2008. Dissertação

Maria Gorete Abdo Leal. O processo de gestão da avaliação institucional em uma IES de Santa Catarina e sua expressão no projeto pedagógico do curso de administração. 2008.

Cristiane Nadaleto. Prática de Ensino, Emoção e Afeto. 2007. Bolsa CAPES

Gracia Maria Nascimento Corrêa. A Educação Condutiva Como Possibilidade De Desenvolvimento E Inserção Social. 2007.

Claudia Maria Petri. Olhares, significações e silêncios: a produção de conhecimentos na prática de ensino. 2006. Bolsa CNPq

Nilzete Teixeira Maçaneiro. O professor e sua profissionalidade docente: investigando sentidos possíveis. 2006.

Rita Bastos Santos. Formação de Professores e a Abordagem Histórico Cultural. 2005.

Miriam Cristina Frey de Lira. Lembranças de Escola: um estudo sobre a inclusão do aluno com diferenças visuais. 2005. 


\section{autêntica}

DOI https://doi.org/10.31639/rbpfp.v10i19.185

Maristela Vanzuita Machado. Professora: sujeito em formação. 2005. Bolsa CAPES

Roslei Aparecida Sinderski Bigaton. Perfil social, economico e cultural dos professores do município de Balneário Camboriu. 2005.

Marcia Regina Cordeiro Bavaresco. As interfaces de um programa oficial de formação: profa - do escrito à dinâmica de formação. 2004.

Mara Muller Jenchen. Escola, Lugar de Rosas e Pitangas. 2004.

Márcia de Souza Hobold. A constituição da profissionalidade docente: um estudo com professores de educação profissional do SENAI. 2004.

Heloísa Maria Wichern zunino. Professoras Alfabetizadoras: concepções e práticas. 2003.

Carla Ferdinanda Gasparac Alves da Silva. A estrutura metodológica de uma classe de aceleração e a construção de conceitos matemáticos. 2003.

Carla Clauber da Silva Ropelato. A fabricação da anormalidade no cotidiano escolar. 2003.

Célia diva Renck Hoefelmann. Grupos de estudo como modalidade de formação continuada para uma educação inclusiva. 2003.

Miriam Cestari Niebuhr. A Formação Inicial e a Educação Inclusiva: um estudo de caso. 2002.

Claudia Renate Ferreira. Projeto pedagógico do curso de pedagogia: impactos da avaliação externa. 2002.

Rita Buzzi Rausch. A Prática Pedagógica nos Primeiros Anos de Escolarização: uma reflexão coletiva sobre a ação mediada em uma perspectiva histórico-cultural. 1999.

\section{TESES DE DOUTORADO DEFENDIDAS:}

Claudete Bonfanti. O estágio na formação de professoras para a educação infantil: as significações das estagiárias de um curso de pedagogia. 2017. Bolsa PDSE/CAPES

Joselma Salazar de Castro. A docência na Educação Infantil como ato pedagógico. 2016. Bolsa PDSE/CAPES Aurea Demaria Silva. Mais ou menos músicos: um estudo sobre o consumo e os modos de produção musical entre jovens. 2013. Bolsa CAPES.

Orientações de estágios de pós-doutoramento:

Julio Romero Rodriguez. 2011. Universidad Complutense, Programa Jose Castillejo.

Rita Buzzy Rausch. 2018. Universidade Regional de Blumenau (FURB). A produção científica sobre formação estética de professores no brasil: metapesquisa das dissertações e teses em educação publicadas no período de 2007 a 2017. Bolsa CAPES (cota do PPGE/UFSC).

\section{ALGUMAS CONSIDERAÇÕES}

Vigotski (2003) nos deixa como legado a necessidade de pensarmos o professor e a criança a partir de suas relações com o conhecimento, com a vida e com a atividade de ensinar e de aprender. O autor, ao questionar as "leis" que orientam a atividade de ensino em seu tempo, afirma que "a ciência é o caminho mais seguro 


\section{autêntica}

DOI https://doi.org/10.31639/rbpfp.v10i19.185

para a vida (...) só a vida educa, e, quanto mais amplamente a vida penetrar na escola, tanto mais forte e dinâmico será o processo educativo" (Vigotski, 2003, p.300).

O processo pedagógico é a vida social ativa, é a troca de vivências combativas, é uma tensa luta em que o professor, no melhor dos casos, personifica uma pequena parte da classe - com frequência, ele está totalmente só. Todos os seus elementos pessoais, toda experiência de sentimentos e pensamentos, além da vontade, são utilizados sem cessar nessa atmosfera de tensa luta social, denominada trabalho pedagógico interno. Sua rede de insatisfações pessoais, de incômodos, de esforços para se aclimatar e sua sinceridade pedagógica, as lições educativas derivadas disso (VIGOTSKI, 2003, p.303).

É possível compreender a atividade de ensino como uma prática social, criativa e viva, pois o professor pode tornar-se aquele que provoca situações em que as crianças possam inspirar-se, nas diferentes vivências. Observar, planejar, avaliar a prática de ensino são atividades fundamentais para o exercício de compreensão da docência.

Parte-se da premissa de que o professor é a variável mais importante e fundamental para se efetivar o processo de ensino e de aprendizagem. E que, neste sentido, há muito que se pesquisar neste campo investigativo.

Qualificar a natureza da função do professor não tem sido tarefa fácil, ao longo da história. Para Roldão (2007), é muito comum atrelar-se o fazer docente à tarefa de ensino e considerar-se o ensino como a transmissão de um saber. Compreendemos a formação docente como um processo que envolve, ao mesmo tempo, o desenvolvimento e a estruturação da pessoa em relação à sua profissão - sua profissionalidade. "Um profissional define-se, no quadro da sociologia das profissões, por diversos caracterizadores: "a clareza acerca da natureza da função e a associação de um saber específico ao exercício dessa função" (ROLDÃO, 2007, p. 35). Entretanto, para pensarmos a docência, ou seja, a atividade do professor como profissão, é preciso considerar que a ação do professor produz uma identidade profissional. A atividade docente exige uma série de ações características e específicas, que geram, no seu conjunto, a ação profissional do professor, e que a diferencia das demais profissões. O valor e o sentido atribuídos ao processo de profissionalização docente vêm sendo construídos historicamente, em um processo dialético, que envolve posicionamentos coletivos e individuais. O movimento de profissionalização docente vem acompanhado de um conjunto de ações, institucionalizadas ou não, que incentivam os professores a se comprometerem com a profissão docente. No contexto da sociedade brasileira, a tarefa do professor é uma tarefa social e política extremamente complexa, exigindo do professor ações e decisões imediatas, observações atentas aos fenômenos emergentes e implícitos no seu fazer. A formação de professores é, portanto, um fenômeno complexo e diverso que envolve, por um lado, a profissionalidade, e, por outro, a ideia de formação como instituição: a estrutura organizacional que planifica e desenvolve as atividades de formação. No entanto, consideramos que a docência é a base da formação, indissociáveis que são a teoria e a prática. O professor exerce um papel essencial na formação da criança e do adolescente. Suas competências e conhecimentos pedagógicos possibilitam a constituição de situações de aprendizagem que oportunizam, no ambiente escolar, vivências diferenciadas e significativas nas quais a criança pode aprender e se desenvolver. Investir na pesquisa sobre a formação de professores significa promover ações que contribuam para sua formação; implica em atender a exigências, tais como equilibrar a teoria e a prática, e contemplar diferentes necessidades, curiosidades, interesses que se apresentam na sua prática cotidiana. 


\section{autêntica}

DOI https://doi.org/10.31639/rbpfp.v10i19.185

\section{REFERÊNCIAS}

BAKHTIN, M. A Estética da Criação Verbal. São Paulo, Martins Fontes, 2003.

BIGATON, Roslei Aparecida Sinderski. Perfil Social, Economico e Cultural dos Professores do Município de Balneário Camboriú. 2005. Dissertação (Mestrado em Mestrado Em Educação) - Universidade do Vale do Itajaí.

BONFATI, C. O estágio na formação de professoras para a educação infantil: as significações das estagiárias do curo de pedagogia. 2017. Doutorado em Educação. Programa de Pós-Graduação em Educação, UFSC, Florianópolis, 2017.

CASTRO, J. S. de. A docência na educação infantil como ato pedagógico. 2016. Doutorado em Educação. Programa de Pós-Graduação em Educação, UFSC, Florianópolis, 2016.

HELLER, A. O Cotidiano e a História. São Paulo: Editora Paz e Terra, 1992.

GUINZBURG, C. Mitos, emblemas, sinais: morfología e história. Trad, de Frederico Carotti. São Paulo: Cia. das Letras 1989

KOZULIN, Alex. La Psicologia de Vygotsky. Madrid, Alianza, 1994.

LATERMAN, I. Ação Docente e Campo de Possibilidades: configuração nos contextos institucional, político e social. Anais da 28 Reunião ANPED. Caxambu:2005. GT: Sociologia da Educação / n.14.

LATERMAN, I. Ação docente nos anos iniciais do ensino fundamental: entre tantas possibilidades. Rev. Teoria e Prática da Educação, v. 13, n. 1, p. 05-18, jan./abr. 2010.

LATERMAN, I.; NUNES, C. M. Brincar e estudar: para além das dicotomias tradicionais. In: Diana Carvalho De Carvalho; Ilana Laterman; Leandro Belinaso Guimarães; Nelita Bertolotto. (Org.). Relações interinstitucionais na formação de professores. 1ed. Araraquara: Junqueira e Marins, 2009, v., p. 31-48.

LATERMAN, I. Que os professores perguntem, testem e brinquem. In: X Congresso Internacional GalegoPortuguês de Psicopedagogia, 2009, BRAGA. Actas do X Congresso Internacional Galego-Português de Psicopedagogia. Braga: Centro de Investigação em Educação (CIEd) Universidade Minho, 2009. v. 1. p. 1246-1257.

LATERMAN, I. Nas asas de freinet: a voz e a vez de todos na vida da escola. In.: Laterman e Agostinho (org.) Perspectivas do estágio curricular na formação docente: educação infantil e anos iniciais do ensino fundamental. Florianópolis: NUP, 2017. P 207-222.

MACHADO, Maristela Vanzuita. Professora: sujeito em formação. 2005. Dissertação (Mestrado em Educação) - Universidade do Vale do Itajaí, 2005.

NADAleto, Cristiane. Prática de Ensino, Emoção e Afeto. 2007. Dissertação (Mestrado em Educação) Universidade do Vale do Itajaí, Bolsa CAPES (Coordenação de Aperfeiçoamento de Pessoal de Nível Superior). 


\section{autêntica}

DOI https://doi.org/10.31639/rbpfp.v10i19.185

OSTROWER, Fayga. Criatividade e Processos de Criação. São Paulo, Vozes, 2007.

PETRI, Claudia Maria. Olhares, Significações e Silêncios: a Produção de Conhecimentos na Prática de Ensino. 2006. Dissertação (Mestrado em Educação) - Universidade do Vale do Itajaí, Bolsa CAPES (Coordenação de Aperfeiçoamento de Pessoal de Nível Superior). Orientadora: Luciane Maria Schlindwein.

PFEIFFER, Karl L. Estética, ou: Proust pode hoje encontrar Farinelli? Revista Filosofia Política - Departamento de Filosofia, Curso de Pós-Graduação em Filosofia IFCH/UFRGS. Rio de Janeiro: Jorge Zahar Ed., 2001. Série III, n.2, p. 86-102.

PINO, Angel, Imaginário e Produção Imaginária: Reflexões em Educação. In: DA ROS, S.Z.; MAHEIRE, K.;ZANELLA, A.V. (Org). Relações estéticas, atividade criadora e imaginação: Sujeitos e (em) experiência. Florianópolis: NUP/CED/UFSC, 2006.

ROLDÃO, Maria do Céu. Função docente: natureza e construção do conhecimento profissional. Revista Brasileira de Educação, v. 12 n. 34 jan./abr. 2007 p. 94-103.

SCHLINDWEIN, Luciane Maria. Perfil dos professores das séries iniciais no município de Balneário Camboriú. 2004a. Relatório de Pesquisa (PIPG).

SCHLINDWEIN, Luciane Maria. Perfil Social Econômico e Cultural dos Professores das Séries Iniciais do Município de Itajaí. 2004b. Relatório de Pesquisa (PIBic).

SCHLINDWEIN, L. M. Formação de Professores, memória e imaginação. In: DA ROS, Silvia Z; MAHEIRIE, Kátia; ZANELLA, Andréa Vieira. (org.) Relações estéticas, atividade criadora e imaginação: sujeitos e (em) experiência. Florianópolis: NUP/CED/UFSC, 2006.

SCHLINDWEIN, Luciane Maria. 2005. Imaginação e Arte na Formação de Professores do Ensino Fundamental. 2005. Relatório de Pesquisa (PIBic).

SCHLINDWEIN, Luciane Maria. 2006-2008. A Formação Estética do Professor do Ensino Básico: o papel da música. Pesquisa em andamento financiada pelo edital Universal da FAPESC.

SCHLINDWEIN, L. M. \& NADALETO, C. Memoriais como instrumentos de Pesquisa e Tomada de Consciência. In: Ética e Metodologia: Pesquisa na Educação. Coleção Plurais Educacionais, $1^{\text {a }}$ ed. Itajaí: Editora UNIVALI e Editora Maria do Cais, 2006, v. 4.

SOARES, Maria Luiza Passos. Educação Estética - Investigando Possibilidades a Partir de um Grupo de Professoras. 2008. Dissertação (Mestrado em Mestrado Em Educação) - Universidade do Vale do Itajaí. Orientador: Angel Pino Sirgado.

VIGOTSKI, L. S. As bases da pedologia. Leningrado, Editora do Instituto Pedagógico de Leningrado, 1935. // Vigotski, L. S. Aulas sobre pedologia. 1933-1934. Iviejsk, Editora da Universidade de Udmursk, 1996. Tradução de Márcia Pileggi Vinha (do original em russo).

VYGOTSKY, L.S. Obras Escogidas, Vol. III. Madrid: Visor, 1995. 


\section{autêntica}

DOI https://doi.org/10.31639/rbpfp.v10i19.185

VIGOTSKY, L. S. A Construção do Pensamento e da Linguagem. São Paulo, Martins Fontes, 2001.

VIGOTSKI, L. S. A Educação Estética. In: Psicologia Pedagógica. Porto Alegre, Artmed, 2003. cap. 13, p.225-248.

VIGOTSKI, L. S. Psicologia da Arte. São Paulo, Martins Fontes, 1999.

VYGOTSKI, L. S. Obras Escogidas. Madrid, Visor, 1982. 